\title{
Depression in patients with refractory temporal lobe epilepsy
}

\author{
Eleonora Borges Gonçalves, Fernando Cendes
}

\begin{abstract}
Objective: To evaluate the comorbidity of depressive disorders in patients with refractory temporal lobe epilepsy (TLE). Method: We evaluated 25 consecutive patients with refractory TLE (16 women and 9 men), using semi-structured psychiatric interviews, according to the International Classification of Diseases (ICD-10), and the Beck Depression Inventory. Results: Seventeen of 25 patients (68\%) had depressive disorder: 6 with dysthymia, three with major depressive episodes and 8 with recurrent depressive disorders. Two (8\%) were diagnosed with mixed anxiety and depression. Only 5 of 17 patients (29.4\%) were previously diagnosed with depressive disorder and received prior antidepressant treatment. Duration of epilepsy was significantly higher in patients with depressive disorder $(p=0.016)$, but there was no relationship between depression and seizure frequency. Conclusion: This study confirmed that depressive disorders are common and underdiagnosed in patients with TLE refractory to AEDs. Patients with longer duration of epilepsy are at higher risk of having depression.
\end{abstract}

Key words: depressive disorders, depression, mesial temporal lobe epilepsy, seizures.

\section{Depressão em pacientes com epilepsia de lobo temporal refratária}

\section{RESUMO}

Objetivo: Avaliar os transtornos depressivos em comorbidade com a epilepsia do lobo temporal (ELT) em pacientes refratários às drogas antiepiléticas (DAE). Método: Avaliamos 25 pacientes consecutivos (16 mulheres e 9 homens) utilizando entrevista psiquiátrica semiestruturada, conferindo diagnóstico segundo a Classificação Internacional de Doenças (CID-10) e o Inventário de Depressão de Beck (BDI). Resultados: Dezessete dos 25 pacientes (68\%) apresentaram transtorno depressivo: 6 com distimia, 3 com episódio depressivo maior e 8 com transtorno depressivo recorrente. Dois (8\%) apresentaram transtorno misto de ansiedade e depressão. Apenas 5 dos 17 pacientes $(29,4 \%)$ com transtorno depressivo receberam tratamento antidepressivo prévio. A duração da epilepsia foi significativamente maior nos pacientes com transtorno depressivo $(p=0,016)$, porém não houve associação entre depressão e frequência de crises. Conclusão: Este trabalho confirma que o transtorno depressivo é frequente e subdiagnosticado em pacientes com ELT refratária às DAEs. Maior duração da epilepsia aumenta o risco de depressão.

Palavras-Chave: transtornos depressivos, depressão, epilepsia do lobo temporal mesial, crises epilépticas.

\section{Correspondence}

Eleonora Borges Gonçalves

Departamento de Neurologia UNICAMP

Cidade Universitária

13083-970 Campinas SP - Brasil

E-mail: eleobgon@hotmail.com

fcendes@unicamp.br

Conflict of interest

The authors report no conflict of interest

Received 4 March 2011

Received in final form 27 April 2011

Accepted 11 May 2011
Epilepsy is a common neurological disorder, associated with increased rates of psychiatric disorders when compared to the general population ${ }^{1}$. Studies suggest that a lifetime history of depressive disorders is relatively frequent in patients with epilepsy $^{2}$, in particular in those with tem- poral lobe epilepsy (TLE) associated with hippocampal sclerosis ${ }^{3-5}$.

Epilepsies are considered refractory when patients do not achieve seizure control with at least two antiepileptic drugs (AEDs) in mono or polytherapy with adequate doses not associated with unaccept- 
able side effects ${ }^{6}$. The frequency of depressive disorders appears to be dependent on the severity of epilepsy and the localization of the epileptogenic focus, with prevalence up to $50 \%$ of patients with refractory TLE ${ }^{1-5}$. Population studies revealed a frequency of depression varying from $9 \%$ to $22 \%$ in patients with epilepsy, while hospital series usually report higher rates of depression (27\% to $58 \%$ ) for patients with epilepsy ${ }^{7}$. For some authors ${ }^{8}$, this prevalence is higher $(60-80 \%)$ in patients with refractory TLE, although this is still controversial ${ }^{4}$. TLE with untreated depressive episodes for a long time may be associated with reduced hippocampal volume in MRI ${ }^{9}$. In addition, mood disorders, especially major depression, have great influence on quality of life in patients with epilepsy ${ }^{5,7,10}$.

While many still consider that depressive disorders in epilepsy is a reaction to the consequences of seizures and stigma, recent studies indicate a complex interaction between neurobiological (including genetic), iatrogenic and psychosocial mechanisms. Furthermore, several studies have suggested the existence of a bidirectional relation between depressive disorders and epilepsy ${ }^{2}$.

The aim of this study was to investigate the types and frequency of mood disorders in a series of consecutive patients with refractory TLE.

\section{METHOD}

\section{Subjects}

We included 25 consecutive patients with refractory TLE; 9 man and 16 women with ages varying from 24 to 57 years (mean age of 39 years). Refractory TLE was considered when seizures were not controlled after at least three adequate antiepileptic drugs (AEDs) regimens with mono or polytherapy.

Patients were considered eligible for participation if they had TLE diagnosed for more than two years, if their seizures were refractory to AEDs, if they had undergone a magnetic resonance image (MRI), serial electroencephalograms (EEGs), and if they agreed to participate in the study and signed the written informed consent approved by the local institutional ethics committee. All were patients from the outpatient clinic of the University of Campinas (UNICAMP). Patients with any other neurological conditions or mental retardation were not included.

All patients underwent a detailed structured psychiatric interview to define clinical diagnosis of mood disorders according to the International Classification of Diseases (ICD-10). In addition to the structured psychiatric interview, we applied the Mini International Neuropsychiatric Interview (MINI) and the Beck Depression Inventory $(\mathrm{BDI})^{11}$. The $\mathrm{BDI}$ was used to evaluate the severity of depressive symptoms. A BDI score above 30 was considered as severe depression and scores between 15 and 30 as moderate depression. The $\mathrm{MINI}^{12,13}$ was used as an additional tool for distinguishing present and past major depressive episodes and dysthymia.

\section{Statistical analyses}

We used t-test to analyze group differences for numerical data and Pearson correlation test to analyze associations between seizure frequency and duration of epilepsy with BDI scores.

\section{RESULTS}

Overall frequency of mood disorders in TLE patients

All patients had clinical and EEG findings of TLE ${ }^{14}$ and were refractory to AEDs ${ }^{15}$. All but two patients had MRI signs of hippocampal sclerosis ${ }^{14}$.

Seventeen of the 25 (68\%) TLE patients had mood disorders classified as follows:

- 6 had dysthymia (ICD-10 F34.1): A chronic depression of mood, lasting at least two years;

- 3 had mood disorder classified as major bipolar affective disorder (ICD-10 F31);

- 8 had recurrent depressive disorder (ICD-10 F33): A disorder characterized by repeated episodes of depression as described for depressive episode, without any history of independent episodes of mood elevation and increased energy (mania). In 4 of these there was an association with organic mood disorders (ICD-10 F06).

Among those with depressive disorder, 5 had BDI scores above 30 , characterizing severe symptoms, with poor prospects for the future, especially in working life and leisure, with suicidal ideation.

Most (70.6\%) of these 17 patients were not previously diagnosed and only $29.4 \%$ received proper antidepressive treatment before the present study.

Two (8\%) patients were diagnosed with mixed symptoms of anxiety and depression (ICD-10 F41.2) but not characterizing depressive disorder. The remaining six patients (24\%) had mild anxiety symptoms.

\section{Relationships between mood disorders and seizure frequency and duration of epilepsy}

There was no difference in age between patients with and without depression $(\mathrm{p}=0.48)$.

This group of patients had long-standing epilepsy with mean duration of 31.8 years $(\mathrm{SD}=8.6)$ and high seizure frequency, with mean of 1.8 seizure per week $(\mathrm{SD}=1.2)$, varying from 5 seizures per week to one seizure every two months.

There was significant longer duration of epilepsy among those with depression (mean of 34.6 years; $\mathrm{SD}=5.7$ ) as compared to those without depression (mean of 26 years; $S D=11 ; p=0.016$ ). In addition, there was a 
significant correlation between BDI scores and duration of epilepsy ( $r=0.4 ; p=0.047)$. However, we found no differences in the seizure frequency between TLE patients with depression versus those without depression $(\mathrm{p}=0.9)$ and no correlation between BDI scores and seizure frequency $(\mathrm{r}=0.09 ; \mathrm{p}=0.64)$.

From the 17 patients with depression, 10 had left TLE, 4 had right TLE and 3 had bilateral TLE based on EEG and MRI data.

\section{DISCUSSION}

The manifestations of depressive disorders in epilepsy have been multifaceted, with many psychological and neurobiological interactions, including clinical characteristics of epilepsy (duration, type and lateralization) and possible neurochemical mechanisms ${ }^{2,7}$. In the present work, frequency and severity of depression in patients with refractory TLE was associated with duration of epilepsy but not with seizure frequency. These relationships have been controversial among studies ${ }^{4,7}$, although it is increasingly more evident that there is a probable bidirectional relationship between depression and $\mathrm{TLE}^{2}$. Along this line, in a recent study with a different series of TLE patients, we found that patients with TLE and depression had more widespread gray matter atrophy than TLE without depression ${ }^{16}$. Although this atrophy was subtle and not observed by regular MRI, it is further evidence for biological factors related to depression in $\mathrm{TLE}^{16}$. In the present study, although the number of patients was small for definite conclusions, we found that depression was more frequent and more severe in patients with left TLE than in right TLE as it was found in other studies ${ }^{7,16}$.

Previous studies have shown that history of depression and attempted suicide increases the risk of later unprovoked seizures in people without epilepsy ${ }^{17,18}$. In addition, a history of psychiatric comorbidity, in particular depression, may be associated to future resistance to AEDs in patients with newly diagnosed epilepsies ${ }^{19}$, and also to poorer response to surgical treatment in patients with $\mathrm{TLE}^{20}$. A lifetime history of depression was the sole predictor of post-surgical auras in seizure-free patients and also a predictor of disabling seizures in those with a poorer outcome. Thus, the brain dysfunction that underlies mood disorders may interact with those producing seizures, in particular temporal lobe seizures ${ }^{2,3}$. This deleterious interaction may worsen through time and it is reasonable to speculate that the longer it takes to control one of the conditions, depression or seizures, the harder it becomes to control the other.

This study adds further evidence that depressive disorders are frequent and underdiagnosed in patients with refractory TLE, and may get worse with longer duration of epilepsy. While it is unclear if early diagnosis and proper treatment of depression may prevent brain dysfunction or help to ameliorate epilepsy itself, it is evident that untreated depression has a great impact on the patient's quality of life. Physicians need to be aware of this frequent comorbidity and be prepared to diagnose and treat depression in their patients with TLE.

ACKNOWLEDGMENTS - The authors thank Elisabeth Borges Gonçalves for discussions about the statistical analyses, and all Medical Residents and Fellows from the department of Neurology, UNICAMP, for their invaluable help in recruiting patients.

\section{REFERENCES}

1. Gillian FG. Diagnosis and treatment of mood disordes in person with epilepsy. Curr Opin Neurol 2005;18:129-133.

2. Kanner AM. Depression in epilepsy: a complex relation with unexpected consequences. Curr Opin Neurol 2008;21:190-194.

3. Shamim S, Hasler G, Liew C, Sato S, Theodore WH. Temporal lobe epilepsy, depression, and hippocampal volume. Epilepsia 2009;50:1067-1071.

4. Sanchez-Gistau V, Pintor L, Sugranyes G, et al. Prevalence of interictal psychiatric disorders in patients with refractory temporal and extratemporal lobe epilepsy in Spain. A comparative study. Epilepsia 2010;51:1309-1313.

5. Schmitz B. Depression and Mania in Patients with Epilepsy. Epilepsia 2005; 46(Suppl 4):S45-S49.

6. Bourgeois BFD. General concepts of medical intractability. In: Luders HO (Ed). Epilepsy surgery. New York: Raven Press, 1998:777-782.

7. Harden CL. The co-morbidity of depression and epilepsy. Epidemiology etiology and treatment. Neurology 2002;59:549-555.

8. Gaitatzis A, Trimble MR, Sander JW. The psychiatric comorbidity of epilepsy. Acta Neurol Scand 2004;110:207-220.

9. Sheline YI, Gado MH, Kraemer HC. Untreated depression and hipocampal volume loss. Am J Psychiatric 2003;160:1516-1518.

10. Kanner AM. Should Neurologist be trained to recognize and comorbid depression of neurologic disorders? Yes. Epilep Behavi 2005;6:303-311.

11. Beck AT, Wardr CH, Mendelson M, et al. An inventory for measuring depression. Arch Gen Psych 1961;4:561-571.

12. Sheehan DV, Lecrubier $Y$, Sheehan $H$, et al. The Mini-Internacional Neuropsychiatric Interview (MINI): The development and validation of a structure Diagnostic Psychiatric Interview for DSM-IV and CID-10. J Clin Psychiatry 1998;59(Suppl 20):S22-S33.

13. Amorim P. Mini Internacional Neuropsychiatric Interview (MINI): validação de entrevista breve para diagnóstico de transtornos mentais. Rev Bras Psiquiatr 2000;22:106-115.

14. Berg AT, Berkovic SF, Brodie MJ, et al. Revised terminology and concepts for organization of seizures and epilepsies: report of the ILAE Commission on Classification and Terminology, 2005-2009. Epilepsia 2010;51:676-685.

15. Kwan P, Arzimanoglou A, Berg AT, et al. Definition of drug resistant epilepsy: consensus proposal by the ad hoc Task Force of the ILAE Commission on Therapeutic Strategies. Epilepsia 2010;51:1069-1077.

16. Salgado $P C B$, Yasuda CL, Cendes F. Neuroimaging changes in mesial temporal lobe epilepsy are magnified in the presence of depression. Epilep Behav 2010;19:422-427.

17. Forsgren L, Nystrom L. An incident case-referent study of epileptic seizures in adults. Epilepsy Res 1990;6:66-81.

18. Hesdorffer DC, Hauser, WA, Olafsson E, Ludvigsson P, Kjartansson O Depression and suicide attempt as risk factors for incident unprovoked seizures. Ann Neurol 2006;59:35-41.

19. Hitiris N, Mohanraj R, Norrie J, Sillsa GJ, Brodie MJ. Predictors of pharmacoresistant epilepsy. Epilepsy Res 2007;75:192-196.

20. Kanner AM. Epilepsy, suicidal behaviour, and depression: do they share common pathogenic mechanisms? Lancet Neurol 2006;5:107-108. 